\title{
Tracheal dimensions in human fetuses: an anatomical, digital and statistical study
}

\author{
Michał Szpinda $\cdot$ Marcin Daroszewski • Alina Woźniak • \\ Anna Szpinda $\cdot$ Celestyna Mila-Kierzenkowska
}

Received: 27 July 2011 / Accepted: 17 September 2011 / Published online: 8 October 2011

(C) The Author(s) 2011. This article is published with open access at Springerlink.com

\begin{abstract}
Purpose Rapid advances in perinatal medicine have resulted in increased number of various tracheo-bronchial interventions on fetal and neonatal airways. The present study was performed to compile normative data for external dimensions of the trachea at varying gestational age.

Materials and methods Using anatomical dissection, digital image analysis (NIS-Elements BR 3.0) and statistical analysis (ANOVA, regression analysis), a range of measurements (prebifurcation and bifurcation lengths, proximal and distal external transverse diameters, proximal external cross-sectional area, and external volume) for the trachea in 73 spontaneously aborted fetuses ( 39 male, 34 female) aged 14-25 weeks was examined.

Results No significant male-female differences were found $(P>0.05)$. The prebifurcation and bifurcation lengths ranged from $8.14 \pm 1.90$ to $20.77 \pm 0.50 \mathrm{~mm}$ and from $2.23 \pm$ 0.25 to $5.77 \pm 0.76 \mathrm{~mm}$, according to the functions $y=-54.291+23.940 \times \ln ($ Age $) \pm 1.681\left(R^{2}=0.78\right)$ and $y=-10.756+4.860 \times \ln \quad($ Age $) \pm 0.731 \quad\left(R^{2}=0.44\right)$, respectively. Their relative growth, expressed as the bifurcation-to-prebifurcation length ratio, was stable from the age of 16 weeks and attained the value $0.22 \pm 0.05$. The proximal external transverse diameter of the trachea was greater (36 fetuses, $49.3 \%$ ), smaller (34 fetuses, $46.6 \%$ ) or
\end{abstract}

M. Szpinda $(\varangle) \cdot$ M. Daroszewski $\cdot$ A. Szpinda

Department of Normal Anatomy,

The Ludwik Rydygier Collegium Medicum,

Karłowicza 24 Street, 85-092 Bydgoszcz, Poland

e-mail: kizanat@cm.umk.pl

A. Woźniak · C. Mila-Kierzenkowska

Department of Medical Biology,

The Nicolaus Copernicus University, Torun, Poland similar ( 3 fetuses, $4.1 \%$ ), when compared to the distal external transverse diameter. The values for proximal and distal transverse diameters ranged from $2.39 \pm 0.04$ to $5.20 \pm 0.17 \mathrm{~mm}$ and from $2.42 \pm 0.20$ to $4.93 \pm 0.08 \mathrm{~mm}$, expressed by the functions: $y=-9.659+4.574 \times \ln$ (Age) $\pm 0.313\left(R^{2}=0.79\right)$ and $y=-10.897+4.984 \times \ln$ (Age) $\pm 0.327\left(R^{2}=0.81\right)$. The values of proximal external cross-sectional area ranged from $3.38 \pm 0.12$ to $15.98 \pm$ $1.04 \mathrm{~mm}^{2}$, according to the linear function $y=-11.798+$ $1.077 \times$ Age $\pm 1.463\left(R^{2}=0.78\right)$. The values of external volume of the trachea ranged from $34.3 \pm 11.6$ to $370.6 \pm 94.1 \mathrm{~mm}^{3}$ and generated the quadratic function $y=-154.589+0.858 \times \mathrm{Age}^{2} \pm 34.196\left(R^{2}=0.87\right)$.

Conclusions The tracheal parameters do not show malefemale differences. The developmental dynamics of prebifurcation and bifurcation lengths and proximal and distal external transverse diameters of the trachea follow linear functions dependent on the natural logarithm of fetal age, its external cross-sectional area-according to a linear function, and its external volume-according to a quadratic function.

Keywords Trachea $\cdot$ Length $\cdot$ External transverse diameter $\cdot$ External cross-sectional area $\cdot$ External volume

\section{Introduction}

Progress in perinatal medicine has led to the early diagnosis and treatment of respiratory diseases, and to the rapid development of fetal airway surgery $[4,9,11,15,19]$.

The normative data for dimensions of the fetal trachea are still far from completed. To data, the growth of length and diameters has been reported as a proportional relationship, being expressed by a straight line $[1,2,5,16,20]$. 
Few studies have assessed internal cross-sectional areas $[3,6,13]$ and internal volumes $[6,13]$ of the trachea derived from chest $\mathrm{CT}$ scans in children and adults. However, no study has investigated external cross-sectional areas and external volumes of the trachea. Therefore, to improve the knowledge of tracheal quantitative morphology, our objectives were to investigate the following:

- age-specific reference intervals for prebifurcation and bifurcation lengths, proximal and distal external transverse diameters, proximal external cross-sectional area, and external volume of the trachea,

- the relative growth of bifurcation length in relation to prebifurcation length (bifurcation-to-prebifurcation length ratio),

- growth curves for normal development of the seven parameters studied,

- the influence of sex on the value of the parameters examined.

\section{Materials and methods}

The study was carried out on 73 human fetuses of both sexes (39 male, 34 female) from spontaneous abortions or stillbirths, aged 14-25 weeks of gestation. Legal and ethical considerations were consistent with the rules of the University Research Ethics Committee (KB 189/2011). The fetal age was estimated on the basis of crown-rump length with reference to Iffy tables [10].

All specimens were immersed in $10 \%$ neutral formalin solution for 12-24 months for preservation. Dissection of the trachea and the main bronchi was performed according to the standard autopsy techniques, under tenfold magnification using a stereoscope with Huygens ocular. The fetuses were free of malformation affecting both laryngotracheal and cardiovascular structures, when assessed on macroscopic examination.

In each fetus, the trachea in situ with a millimeter scale was placed vertically to the optical lens axis, then recorded using Nikon D200 camera, and digitalized to TIFF images. Next, digital pictures of the trachea (Fig. 1) underwent quantitative analysis using digital image analysis (NIS-Elements BR 3.0, Nikon). At first length, proximal and distal external transverse diameters were measured, and after that cross sections (Fig. 2) were taken between the cricoid cartilage and the first tracheal cartilage rings.

For each subject the seven following measurements and calculations of the trachea were performed:

1. prebifurcation length, corresponding to the distance between the superior border of the first tracheal cartilage and the inferior border of the last tracheal cartilage,

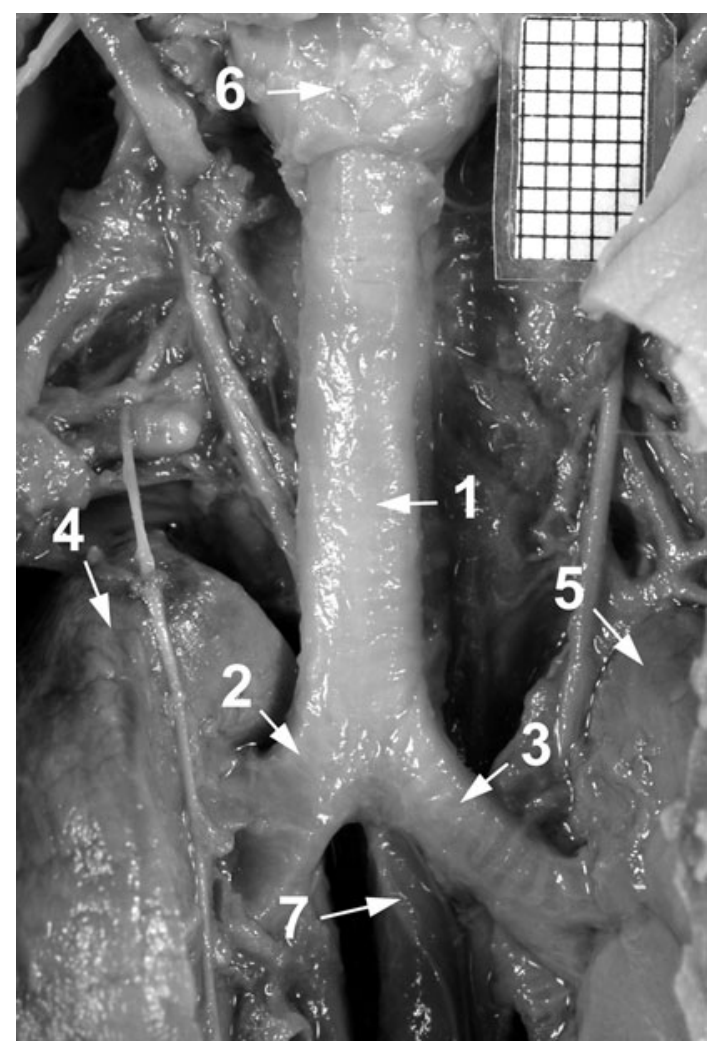

Fig. 1 The trachea and main bronchi in a male fetus aged 24 weeks: 1 trachea, 2 right main bronchus, 3 left main bronchus, 4 right lung, 5 left lung, 6 larynx, 7 esophagus

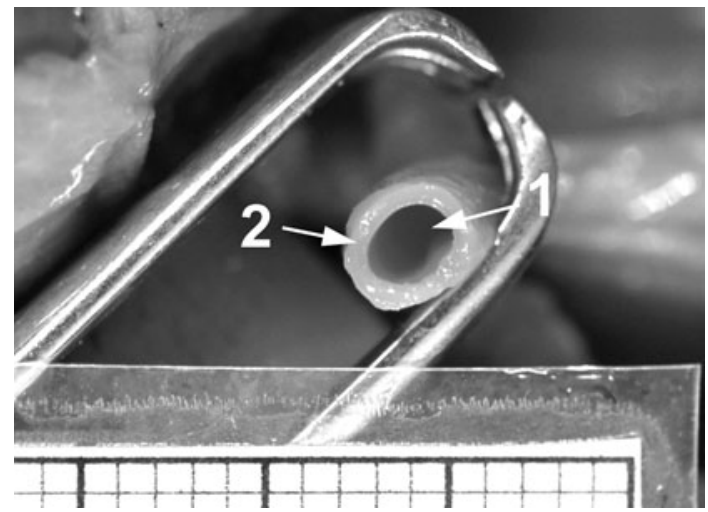

Fig. 2 The trachea in cross section at the level of the first tracheal cartilage in a male fetus aged 18 weeks: 1 tracheal lumen, 2 tracheal wall

2. bifurcation length, corresponding to the distance between the inferior border of the last tracheal cartilage and the tracheal bifurcation,

3. bifurcation-to-prebifurcation length ratio,

4. proximal external transverse diameter, measured at the level of the first tracheal cartilage,

5. distal external transverse diameter, measured at the level of the last tracheal cartilage,

6. proximal external cross-sectional area, traced around the external border of the first tracheal cartilage, 
Table 1 Morphometric parameters of the fetal trachea

\begin{tabular}{|c|c|c|c|c|c|c|c|c|c|c|c|c|c|}
\hline \multirow[t]{3}{*}{$\begin{array}{l}\text { Fetal age } \\
\text { (weeks) }\end{array}$} & \multirow[t]{3}{*}{$\begin{array}{l}\text { Number } \\
\text { of fetuses } \\
\text { (n) }\end{array}$} & \multirow{2}{*}{\multicolumn{2}{|c|}{$\begin{array}{l}\text { Prebifurcation length } \\
(\mathrm{mm})\end{array}$}} & \multirow{2}{*}{\multicolumn{2}{|c|}{$\begin{array}{l}\text { Bifurcation } \\
\text { length }(\mathrm{mm})\end{array}$}} & \multicolumn{4}{|c|}{$\begin{array}{l}\text { External transverse diameter } \\
(\mathrm{mm})\end{array}$} & \multirow{2}{*}{\multicolumn{2}{|c|}{$\begin{array}{l}\text { External } \\
\text { cross-sectional } \\
\text { area }\left(\mathrm{mm}^{2}\right)\end{array}$}} & \multirow{2}{*}{\multicolumn{2}{|c|}{ External volume $\left(\mathrm{mm}^{3}\right)$}} \\
\hline & & & & & & \multicolumn{2}{|c|}{ Proximal } & \multicolumn{2}{|l|}{ Distal } & & & & \\
\hline & & Mean & SD & Mean & SD & Mean & SD & Mean & SD & Mean & $\mathrm{SD}$ & Mean & SD \\
\hline 14 & 2 & 8.14 & 1.90 & 2.23 & 0.25 & 2.39 & 0.04 & 2.42 & 0.20 & 3.38 & 0.12 & 34.3 & 11.6 \\
\hline 15 & 1 & 9.66 & & 2.58 & & 3.00 & & 2.23 & & 5.32 & & & \\
\hline 16 & 2 & 12.38 & 2.02 & 2.75 & 1.18 & 2.91 & 0.24 & 2.94 & 0.23 & 5.02 & 0.83 & 78.1 & 19.3 \\
\hline 17 & 9 & 14.37 & 2.77 & 2.80 & 0.85 & 3.17 & 0.36 & 3.18 & 0.42 & 6.01 & 1.38 & & \\
\hline 18 & 10 & 14.96 & 0.89 & 3.51 & 0.76 & 3.57 & 0.33 & 3.55 & 0.43 & 7.59 & 1.40 & 146.0 & 40.9 \\
\hline 19 & 7 & 17.26 & 0.92 & 3.68 & 0.81 & 3.95 & 0.33 & 3.84 & 0.20 & 9.29 & 1.54 & & \\
\hline 20 & 13 & 17.35 & 2.03 & 4.05 & 0.89 & 4.06 & 0.39 & 4.05 & 0.48 & 9.83 & 1.88 & 197.5 & 43.1 \\
\hline 21 & 11 & 18.12 & 1.83 & 3.70 & 0.56 & 4.27 & 0.31 & 4.22 & 0.43 & 10.80 & 1.53 & & \\
\hline 22 & 5 & 20.42 & 1.91 & 3.97 & 0.80 & 4.53 & 0.21 & 4.54 & 0.18 & 12.17 & 1.15 & 296.1 & 58.2 \\
\hline 23 & 6 & 20.63 & 3.00 & 4.55 & 1.48 & 4.92 & 0.73 & 4.82 & 0.38 & 14.57 & 4.32 & & \\
\hline 24 & 5 & 22.25 & 0.87 & 4.62 & 0.19 & 5.06 & 0.59 & 5.00 & 0.47 & 15.28 & 3.69 & 370.6 & 94.1 \\
\hline 25 & 2 & 20.77 & 0.50 & 5.77 & 0.76 & 5.20 & 0.17 & 4.93 & 0.08 & 15.98 & 1.04 & & \\
\hline
\end{tabular}

Table 2 An increase in values (per week) of morphometric parameters of the fetal trachea

\begin{tabular}{|c|c|c|c|c|}
\hline \multirow{2}{*}{$\begin{array}{l}\text { Fetal age } \\
\text { (weeks) }\end{array}$} & \multirow{2}{*}{$\begin{array}{l}\text { Prebifurcation } \\
\text { length (mm } \\
\text { per week) }\end{array}$} & \multirow{2}{*}{$\begin{array}{l}\text { Bifurcation } \\
\text { length (mm } \\
\text { per week) }\end{array}$} & \multicolumn{2}{|c|}{ External transverse diameter } \\
\hline & & & $\begin{array}{l}\text { Proximal } \\
\text { (mm per week) }\end{array}$ & $\begin{array}{l}\text { Distal } \\
\text { (mm per week) }\end{array}$ \\
\hline 14 & 1.65 & 0.34 & 0.32 & 0.34 \\
\hline 15 & 1.55 & 0.31 & 0.30 & 0.32 \\
\hline 16 & 1.45 & 0.29 & 0.28 & 0.30 \\
\hline 17 & 1.37 & 0.28 & 0.26 & 0.28 \\
\hline 18 & 1.29 & 0.26 & 0.25 & 0.27 \\
\hline 19 & 1.23 & 0.25 & 0.23 & 0.26 \\
\hline 20 & 1.17 & 0.24 & 0.22 & 0.24 \\
\hline 21 & 1.11 & 0.23 & 0.21 & 0.23 \\
\hline 22 & 1.06 & 0.22 & 0.20 & 0.22 \\
\hline 23 & 1.02 & 0.21 & 0.19 & 0.21 \\
\hline 24 & 0.98 & 0.20 & 0.19 & 0.20 \\
\hline
\end{tabular}

7. external volume, calculated by multiplying the sum of prebifurcation and bifurcation lengths by proximal external cross-sectional area.

All the parameters studied were plotted against fetal age so as to establish their growth. Finally, the results obtained were evaluated by the one-way ANOVA test for unpaired data and post hoc Bonferroni test. Regression analysis was used to derive the curve of best fit for each parameter versus gestational age. Coefficients of determination $\left(R^{2}\right)$ between each parameter and fetal age were estimated.

\section{Results}

The results obtained are presented in Tables 1 and 2, and Figs. 3, 4, 5, 6, 7, 8, 9. The statistical analysis of examined features of the trachea revealed no sex differences $(P>0.05)$. Hence the morphometric values studied, regardless of sex, are included in Table 1. Conversely, the growth curves of best fit for the plot for each parameter studied against gestational age were statistically significant $(P=0.0000)$.

During the study period, the values of prebifurcation length ranged from $8.14 \pm 1.90$ to $20.77 \pm 0.50 \mathrm{~mm}$. The growth of prebifurcation length (Fig. 3) followed the linear function dependent on the natural logarithm of fetal age: $y=-54.291+23.940 \times \ln ($ Age $) \pm 1.681\left(R^{2}=0.78\right)$.

The values of bifurcation length rose from $2.23 \pm 0.25$ to $5.77 \pm 0.76 \mathrm{~mm}$, according to the function: $y=$ $-10.756+4.860 \times \ln ($ Age $) \pm 0.731\left(R^{2}=0.44\right)$ (Fig. 4).

To take into account the relative tracheal growth, we calculated the bifurcation-to-prebifurcation length ratio. 


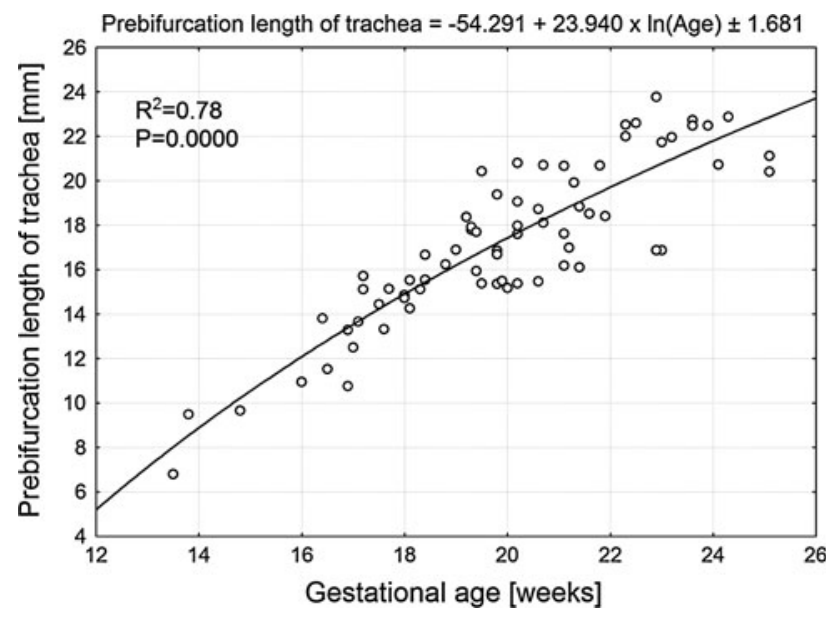

Fig. 3 Regression line for prebifurcation length of the trachea versus gestational age

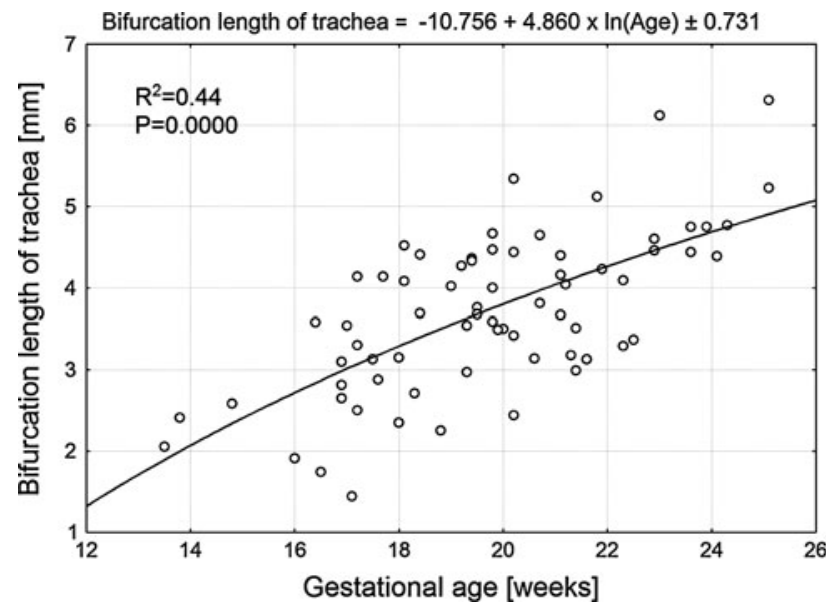

Fig. 4 Regression line for bifurcation length of the trachea versus gestational age

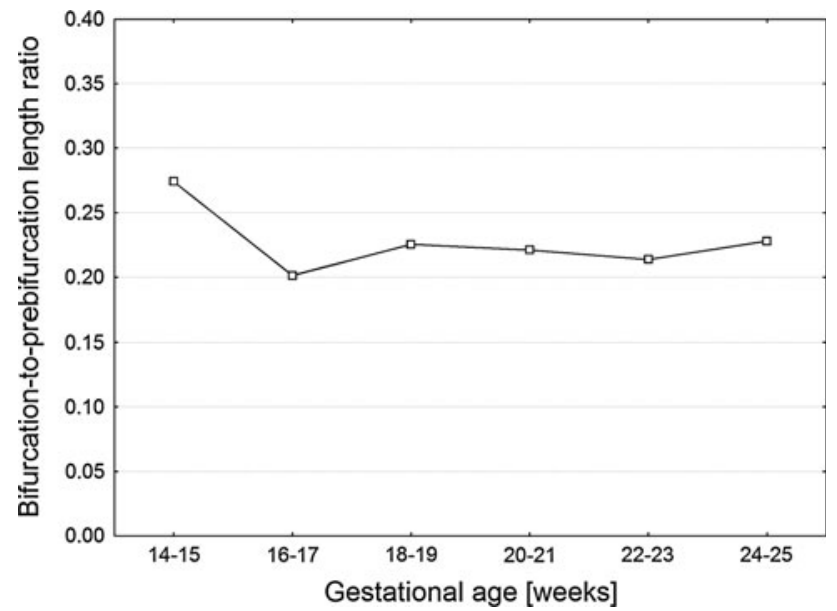

Fig. 5 Bifurcation-to-prebifurcation length ratio of the trachea versus gestational age

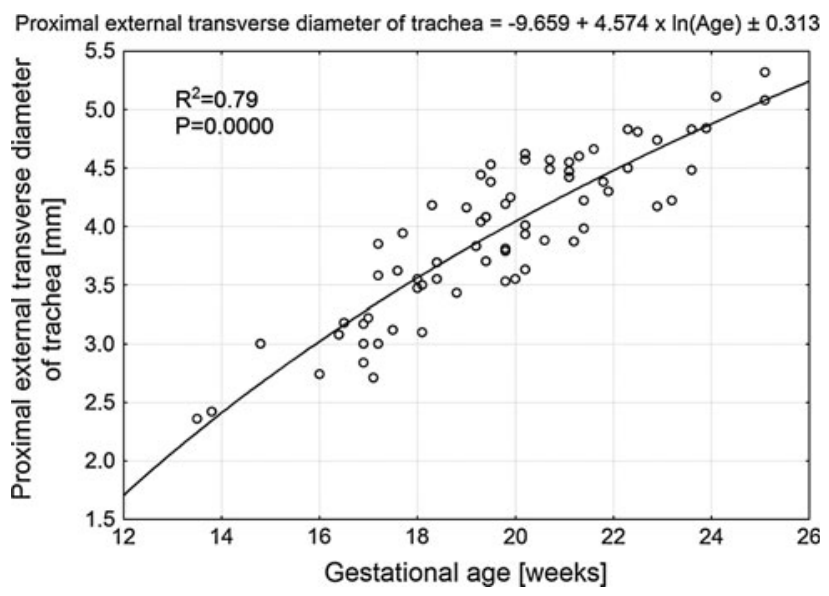

Fig. 6 Regression line for proximal external transverse diameter of the trachea versus gestational age

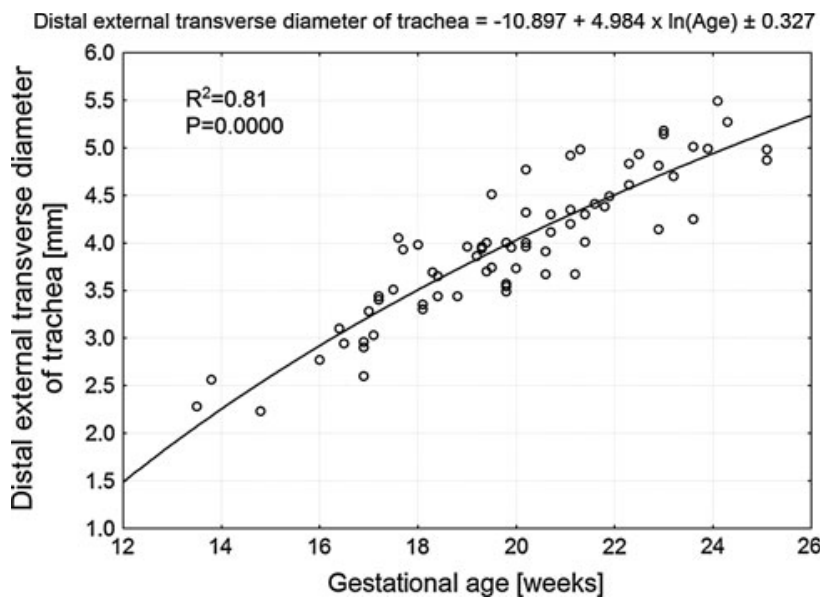

Fig. 7 Regression line for distal external transverse diameter of the trachea versus gestational age

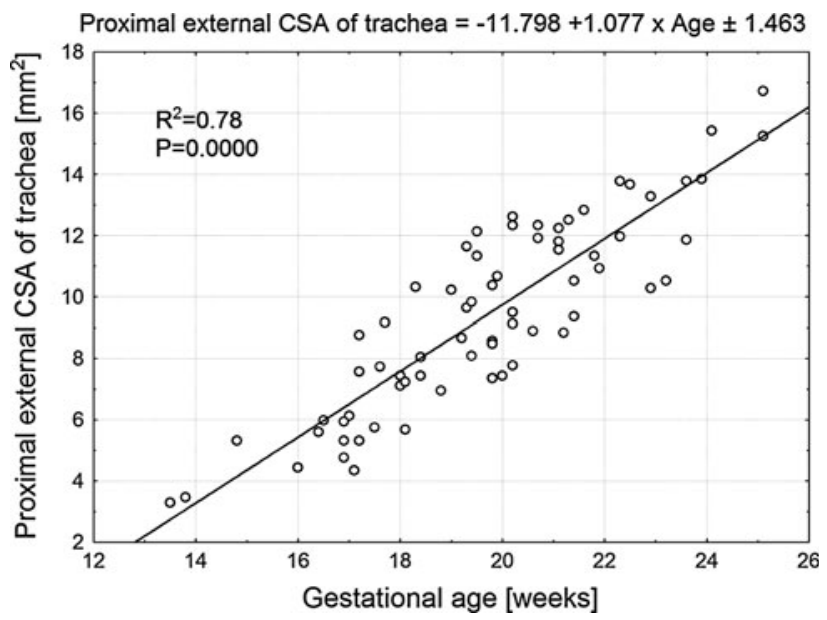

Fig. 8 Regression line for proximal external cross-sectional area of the trachea versus gestational age 


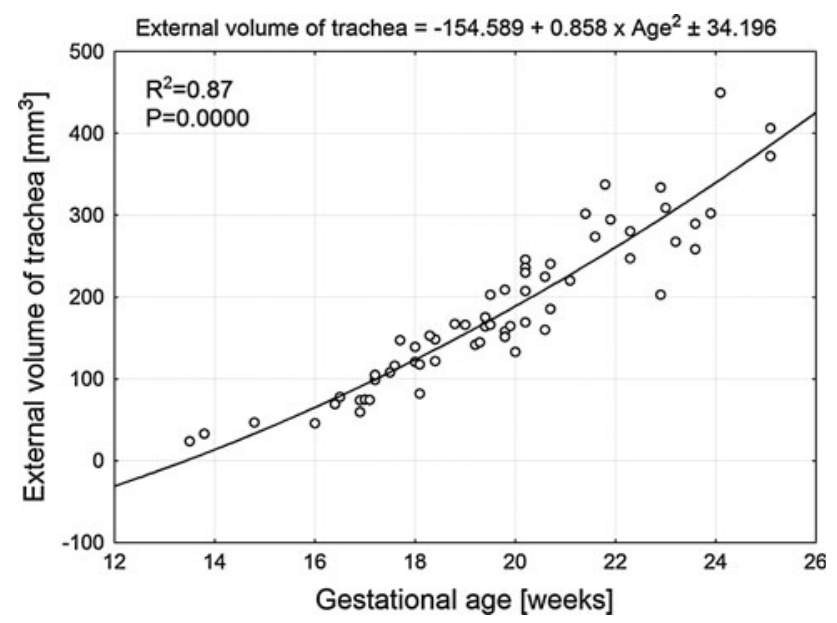

Fig. 9 Regression line for external volume of the trachea versus gestational age

Despite an increase in values of the two lengths studied, their relative growth expressed as the bifurcation-to-prebifurcation length ratio, plotted against gestational age, was stable from the age of 16 weeks and attained the value $0.22 \pm 0.05$ (Fig. 5).

Proximal external transverse diameters of the trachea were greater (36 fetuses, $49.3 \%$ ), smaller (34 fetuses, $46.6 \%$ ) or the same ( 3 fetuses, $4.1 \%$ ), when compared to distal external transverse diameters. The values for proximal transverse diameter ranged from $2.39 \pm 0.04$ to $5.20 \pm 0.17 \mathrm{~mm}$ for the fetuses at 14 and 25 weeks of gestation, respectively. These results showed that proximal external transverse diameter as a function of fetal age (Fig. 6) was expressed by the regression $y=-9.659+4.574 \times \ln \quad($ Age $) \pm 0.313 \quad\left(R^{2}=0.79\right)$. The increase in values of distal external transverse diameter ranged from $2.42 \pm 0.20$ to $4.93 \pm 0.08 \mathrm{~mm}$, and modeled the regression $y=-10.897+4.984 \times \ln \quad($ Age $) \pm 0.327$ $\left(R^{2}=0.81\right)$ (Fig. 7).

The growth dynamics of both the two tracheal lengths and external diameters were decreasing with advanced fetal age. When compared ages of 15 and 24 weeks, the growth (per week) in values was considerably smaller for each parameter, as follows: 1.65 versus 0.98 for prebifurcation length, 0.34 versus 0.20 for bifurcation length, 0.32 versus 0.19 and 0.34 versus 0.20 for proximal and distal external transverse diameters, respectively.

During the study period, the values of proximal external cross-sectional area for the trachea ranged from $3.38 \pm 0.12$ to $15.98 \pm 1.04 \mathrm{~mm}^{2}$, according to the linear function $y=-11.798+1.077 \times$ Age $\pm 1.463\left(R^{2}=0.78\right)($ Fig. 8).

The values of its external volume ranged from $34.3 \pm 11.6 \mathrm{~mm}^{3}$ in fetuses aged $14-15$ weeks to $370.6 \pm 94.1 \mathrm{~mm}^{3}$ in fetuses aged $24-25$ weeks. The external volumetric growth of the trachea generated the quadratic function $y=-154.589+0.858 \times \mathrm{Age}^{2} \pm 34.196$ $\left(R^{2}=0.87\right)$ (Fig. 9).

\section{Discussion}

Reference data for tracheal length and external transverse diameters are scarce in human fetuses. In this anatomical study, digital image analysis (NIS-Elements BR 3.0) was used for measuring tracheal morphometric parameters in fetuses at the age of 14-25 weeks. No significant malefemale differences for any of tracheal parameters were found in our sample, in keeping with the findings of some authors $[1,8,14,16]$ in relation to length and external diameters of the trachea. Conversely, significant sex differences in those tracheal measurements, being greater in males, were found in children [17], adolescents [7], and adults $[12,18]$.

A particular strength of this study results from the large number $(n=73)$ of fetuses used to generate the growth curves. Of note, several transformations concerning tracheal length and diameters against fetal age were generated, but it was proven to be a non-linear correlation, being best described as a linear function dependent on the natural logarithm of age. Analysis of the variance revealed that these non-linear models were highly significant statistically (for each parameter $P<0.001$ ). However, most authors $[1,4,5$, 16] reported that both length and diameters of the trachea increased with advanced fetal age in a proportional fashion, being best described as a straight line. Fayoux et al. [5] presented linear relationships between tracheal length or diameter and fetal age, but without giving precise regression equations. Thus, based on Fig. 4 given by these authors, we calculated ourselves the following formula $y=0.909 \times$ Age +0.61 for tracheal length. Therefore, the present findings are not compatible with those autopsy studies, and provides novel data about the developmental dynamic of the parameters studied. This difference could be accounted for different methods of measurements used in those studies. Reference intervals for both prebifurcation and bifurcation lengths were constructed as follows: from $8.14 \pm 1.90$ to $20.77 \pm 0.50 \mathrm{~mm}$ and from $2.23 \pm 0.25$ to $5.77 \pm 0.76$ mm. According to Harjeet et al. [8], the tracheal length (related to prebifurcation length) was $12.72 \pm 2.50 \mathrm{~mm}$ in fetuses with a crown-to-rump length (CRL) of $61-130 \mathrm{~mm}$, $17.48 \pm 2.89 \mathrm{~mm}$ in fetuses with a CRL of $131-200 \mathrm{~mm}$, and $24.17 \pm 2.30 \mathrm{~mm}$ in fetuses with a CRL of 201$270 \mathrm{~mm}$. It is noteworthy, that the three groups of fetuses were related to ages of 13-18 weeks, 19-24 weeks, and 25-31 weeks, respectively. Therefore, the above mentioned results were smaller than those recorded in the present study.

In the material under examination, the tracheal growth was precisely expressed by the regressions: $y=-54.291+$ $23.940 \times \ln (\mathrm{Age}) \pm 1.681$ for prebifurcation length and $y=-10.756+4.860 \times \ln ($ Age $) \pm 0.731$ for bifurcation length. Nevertheless as indicated in Fig. 5, both lengths 
studied revealed a proportional evolution, since the bifurcation-to-prebifurcation length ratio did not change its value $(0.22 \pm 0.05)$ throughout the study period.

According to our results, the external transverse diameters of the trachea were found to increase from $2.39 \pm 0.04$ to $5.20 \pm 0.17 \mathrm{~mm}$ and from $2.42 \pm 0.20$ to $4.93 \pm$ $0.08 \mathrm{~mm}$ for proximal and distal ends of the trachea, respectively. Our numerical data are consistent with results obtained by Harjeet et al. [8]. In the three groups of fetuses aged 13-18, 19-24, and 25-31 weeks, the values of proximal transverse diameter were $3.26 \pm 0.68 \mathrm{~mm}, 4.42 \pm 0.64 \mathrm{~mm}$, and $5.35 \pm 0.42 \mathrm{~mm}$, respectively. We calculated the growth of proximal transverse diameter of the trachea in the material reported by Fayoux et al. [5], which followed the function $y=0.083 \times$ Age +1.67 . However, our measurements of tracheal diameters show their dependence on fetal age in accordance with the functions $y=-9.659+$ $4.574 \times \ln ($ Age $) \pm 0.313$ for proximal external transverse diameter and $y=-10.897+4.984 \times \ln ($ Age $) \pm 0.327$ for the distal one. It should be emphasized that the growth in values for each parameter was smaller and smaller (Table 2) between ages of 14 and 25 weeks, that is in accordance with the course of a linear function dependent on the natural logarithm of age.

Among the tracheal parameters that we were able to measure, neither proximal external cross-sectional area nor external volume have so far been assessed in the literature. In the current study, we have shown that the proximal external cross-sectional area of the trachea varied between $3.38 \pm 0.12$ and $15.98 \pm 1.04 \mathrm{~mm}^{2}$, in accordance with the function $y=-11.798+1.077 \times$ Age \pm 1.463 . Beyond doubt, the values of proximal external cross-sectional area of the trachea in the material under examination were much smaller than the values of its internal cross-sectional area $\left(20-28 \mathrm{~mm}^{2}\right)$ recorded in neonates $[3,6]$.

As far as the external tracheal volume is concerned, it was found to increase from $34.3 \pm 11.6 \mathrm{~mm}^{3}$ in fetuses aged $14-15$ weeks to $370.6 \pm 94.1 \mathrm{~mm}^{3}$ in fetuses aged 24-25 weeks, being related to the function $y=-154.589+$ $0.858 \times \mathrm{Age}^{2} \pm 34.196$. The quadratic function turned out to be the best growth model for external volume of the trachea $\left(R^{2}=0.87\right)$. In our sample, the external volume of the trachea increased about 11 -fold, which was related to the product of the tracheal length and its proximal external cross-sectional area that increased approximately 2.6-fold and 4.7-fold, respectively. Our recent studies, which are in progress, support the fact that the external volumetric growth is as many as about three times stronger than its internal volumetric growth. This fact is likely to be the consequence of an intensive evolution of tracheal wall thickness, which relatively reduces tracheal luminal volume.

The current autopsy study can be of interest to establish diagnostic criteria for tracheal malformations.

\section{Conclusions}

1. The tracheal parameters do not show male-female differences.

2. The developmental dynamics of prebifurcation and bifurcation lengths, and proximal and distal external transverse diameters of the trachea follow linear functions dependent on the natural logarithm of fetal age, its proximal external cross-sectional area-according to a linear function and its external volume-according to a quadratic function.

Conflict of interest The authors declare that they have no conflict of interest.

Open Access This article is distributed under the terms of the Creative Commons Attribution Noncommercial License which permits any noncommercial use, distribution, and reproduction in any medium, provided the original author(s) and source are credited.

\section{References}

1. Adamiec E, Dzięciołowska-Baran E, Czerwiński F, Miklaszewska D, Teul I (2002) Prenatal development of the human trachea. Folia Morphol 61:123-125

2. Chiba T, Albanese CT, Farmer DL, Dowd CF, Filly RA, Machin GA, Harrison M (2000) Balloon tracheal occlusion for congenital diaphragmatic hernia: experimental studies. J Pediatr Surg 35:1566-1570

3. Effmann EL, Fram EK, Vock P, Kirks DR (1983) Tracheal cross-sectional area in children: CT determination. Radiology 149:137-140

4. Fayoux P, Devisme L, Merrot O, Marciniak B (2006) Determination of endotracheal tube size in a perinatal population: an anatomical and experimental study. Anesthesiology 104:954-960

5. Fayoux P, Marciniak B, Devisme L, Storme L (2008) Prenatal and early postnatal morphogenesis and growth of human laryngotracheal structures. J Anat 213:86-92

6. Griscom NT, Wohl ME (1986) Dimensions of the growing trachea related to age and gender. Am J Roentgenol 146:233-237

7. Hamill PV, Drizd TA, Johnson CL, Reed RB, Roche AF, Moore WM (1979) Physical growth: National Center for Health Statistics percentiles. Am J Clin Nutr 32:607-629

8. Harjeet J, Sahni D, Batra YK, Rajeev S (2008) Anatomical dimensions of trachea, main bronchi, subcarinal and bronchial angles in fetuses measured ex vivo. Paediatr Anaesth 18:1029-1034

9. Harrison MR, Keller RL, Hawgood SB, Kitterman JA, Sandberg PL, Farmer DL, Lee H, Filly RA, Farrell JA, Albanese CT (2003) A randomized trial of fetal endoscopic tracheal occlusion for severe fetal congenital diaphragmatic hernia. N Engl J Med 349:1916-1924

10. Iffy L, Jakobovits A, Westlake W, Wingate M, Caterini H, Kanofsky P, Menduke H (1975) Early intrauterine development: I. The rate of growth of Caucasian embryos and fetuses between the 6th and 20th weeks of gestation. Pediatrics 56:173-186

11. Jani J, Gratacós E, Greenough A, Pieró JL, Benachi A, Harrison M, Nicolaïdes K, Deprest J (2005) Percutaneous fetal endoscopic tracheal occlusion (FETO) for severe left-sided congenital diaphragmatic hernia. Clin Obstet Gynecol 48:910-922

12. Jit H, Jit I (2000) Dimensions and shape of the trachea in the neonates, children and adults in northwest India. Indian $\mathrm{J}$ Med Res 112:27-33 
13. Kamel KS, Lau G, Stringer MD (2009) In vivo and in vitro morphometry of the human trachea. Clin Anat 22:571-579

14. Kher GA, Makhani JS (1960) A preliminary study of the lengths of the two main bronchi and angle at the carina. J Indian Med Assoc 34:262-265

15. Kohl T, Hering R, Bauriedel G, Van de Vondel P, Heep A, Keiner S, Müller A, Franz A, Bartmann P, Gembruch U (2006) Fetoscopic and ultrasound-guided decompression of the fetal trachea in a human fetus with Fraser syndrome and congenital high airway obstruction syndrome (CHAOS) from laryngeal atresia. Ultrasound Obstet Gynecol 27:84-88
16. Menu Y, Lallemand D (1981) Determination of the normal transverse diameter of the trachea in childhood. Ann Radiol 24:73-75

17. Pagtakhan AD, Bjelland JC, Landau LI, Kaltenborn W, Seeley G, Taussig LM (1984) Sex differences in growth patterns of the airways and lung parenchyma in children. J Appl Physiol 56:1204-1210

18. Randestad A, Lindholm CE, Fabian P (2000) Dimensions of the cricoid cartilage and the trachea. Laryngoscope 110:1957-1961

19. Wagner W, Harrison MR (2002) Fetal operations in the head and neck area: current state. Head Neck 24:482-490

20. Wailoo MP, Emery JL (1982) Normal growth and development of the trachea. Thorax 37:584-587 